\title{
UNDER THE MICROSCOPE
}

PJOHE

Jonathan P. Rivera, MD'

Jose M. Carnate, Jr., MD²

'Department of Laboratories

Philippine General Hospital

University of the Philippines Manila

${ }^{2}$ Department of Pathology

College of Medicine

University of the Philippines Manila

Correspondence: Dr. Jose M. Carnate, Jr.

Department of Pathology

College of Medicine, University of the Philippines Manila

547 Pedro Gil St. Ermita, Manila 1000

Philippines

Phone (632) 5264450

Telefax (632) 4003638

Email:jmcjpath@gmail.com

The authors declared that this represents original material that is not being considered for publication or has not been published or accepted for publication elsewhere, in full or in part, in print or electronic media; that the manuscript has been read and approved by the authors, that the requirements for authorship have been met by each author, and that the authors believe that the manuscript represents honest work.

Disclosures: The authors signed a disclosure that there are no financial or other (including personal) relationships, intellectual passion, political or religious beliefs, and institutional affiliations that might lead to conflict of interest.

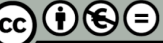

\section{Sinonasal Tract Meningioma}

A 63-year-old Filipino female presented with epistaxis of undisclosed duration. Examination showed a vascular, pulsating, rubbery intranasal mass involving both nasal cavities. The clinical impression was that of a nasal hemangioma. She underwent excision of the tumor and the specimen was sent for histopathologic evaluation.

The specimen consisted of several tan-brown irregular tissue fragments with an aggregate diameter of $2 \mathrm{~cm}$. Microscopic examination showed a cellular spindle cell tumor underneath the respiratory mucosa. (Figure 1) The tumor cells formed a syncytial pattern arranged in whorls that were separated by thin fibrovascular bands. (Figure 2) The cells had round to oval nuclei with nuclear clearing and moderate amount of syncytial cytoplasm compatible with a meningothelial derivation. (Figure 3) There was absence of nuclear atypia, significant mitotic activity and necrosis. Immunohistochemistry studies showed positivity for Epithelial Membrane Antigen (EMA) and Progesterone Receptors (PR) and absence of reaction for Smooth Muscle Actin (SMA) and CD34. (Figure 4) Our diagnosis was sinonasal tract meningioma.

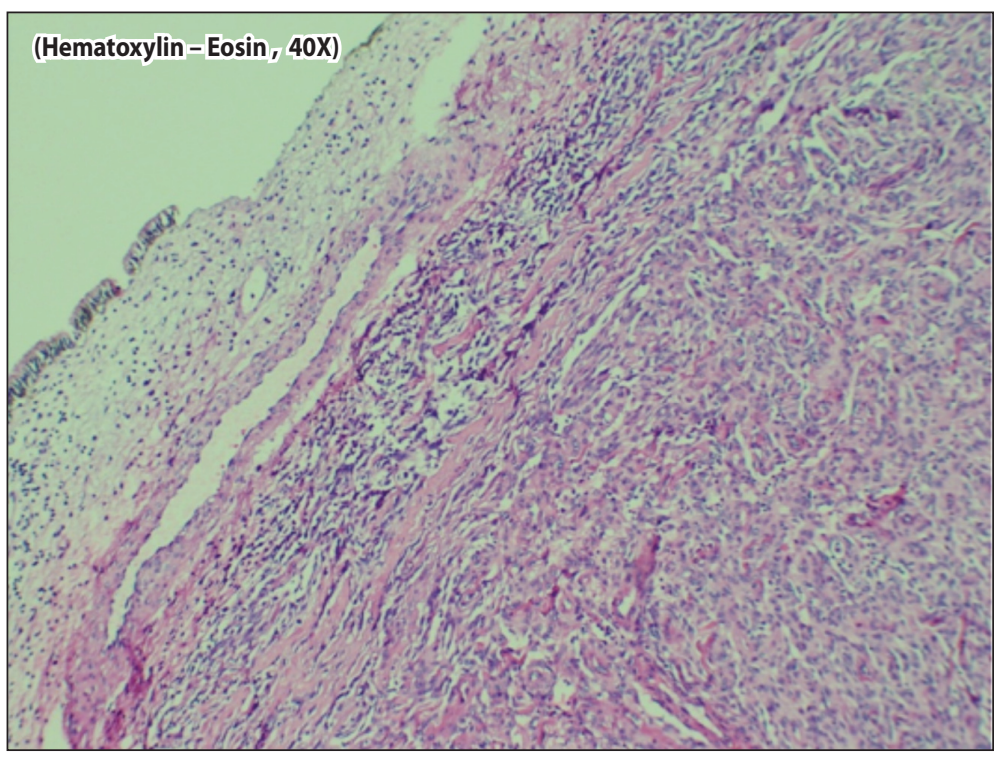

Figure 1. Cellular spindle cell tumor underneath the respiratory mucosa (Hematoxylin-eosin, 40X magnification)

Primary extracranial meningioma of the sinonasal cavity is rare and thus secondary extension from a primary intracranial tumor should be ruled out. It involves a wide age range with no striking gender predilection. ${ }^{1,2}$ Most common symptoms include nasal obstruction, epistaxis, exophthalmos and a mass. Etiogenesis is not completely established and is postulated to arise from meningocytes that are entrapped during closure of midline structures very similar to the development of meningoceles. ${ }^{3}$ 


\section{UNDER THE MICROSCOPE}

Histopathologic examination discloses a spindle cell tumor arranged predominantly in whorls composed of cells showing meningothelial differentiation. Most are histologically grade 1 tumors. Grade 2 and 3 sinonasal tract meningiomas are rare. ${ }^{4}$ Histologic differential diagnoses include a glomangiopericytoma, leiomyosarcoma and a solitary fibrous tumor/hemangiopericytoma. Close histologic evaluation with appropriate immunohistochemistry studies point to the correct diagnosis. Meningioma shows strong diffuse positivity with EMA and PR, and is usually negative for other immunohistochemistry markers such

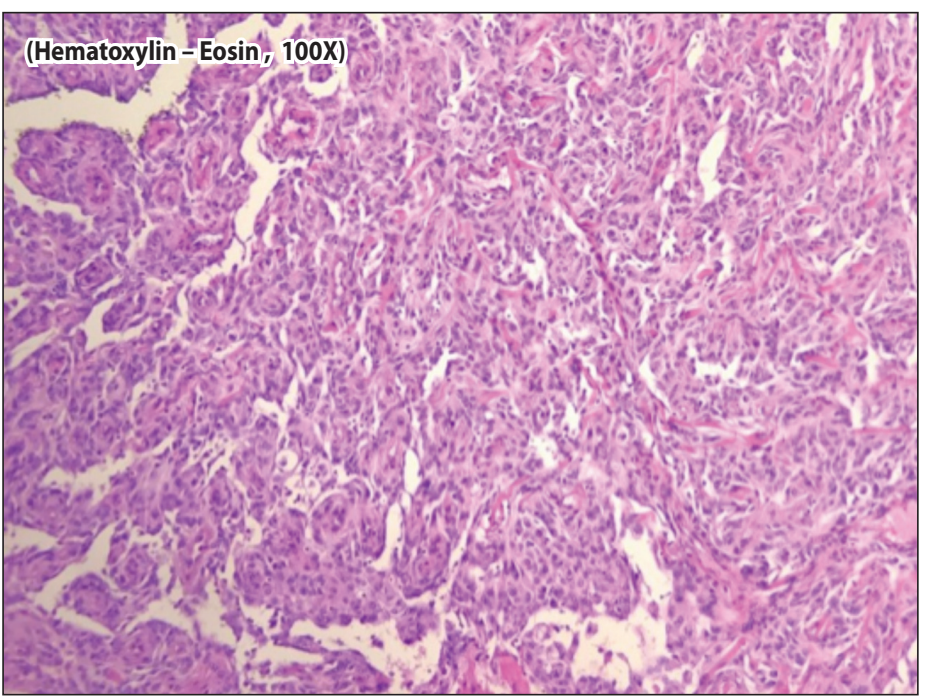

Figure 2. Cellular whorls of tumor cells with occasional intervening fibrovascular bands (Hematoxylin eosin, 100X magnification)

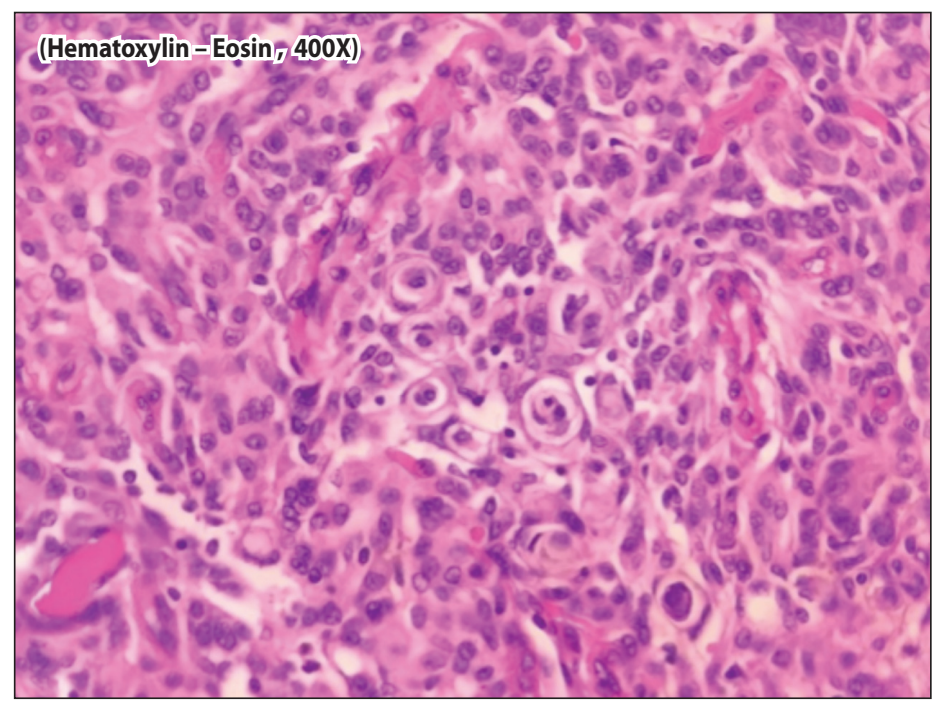

Figure 3. Whorled pattern with cellular features indicative of a meningothelial differentiation (Hematoxylin-eosin, 400X magnification) as muscle actins (for glomangiopericytoma and leiomyosarcoma), and CD34 (for solitary fibrous tumor/hemangiopericytoma). ${ }^{1,3}$ A diagnosis of primary sinonasal meningioma should not be made if an intracranial mass is identified. ${ }^{4}$

Sinonasal meningiomas are benign tumors with no documented distant metastases. ${ }^{1,2}$ Although recurrences occur in about 30\% (mostly due to incomplete excision), metastasis and malignant transformation has not been reported. ${ }^{4}$

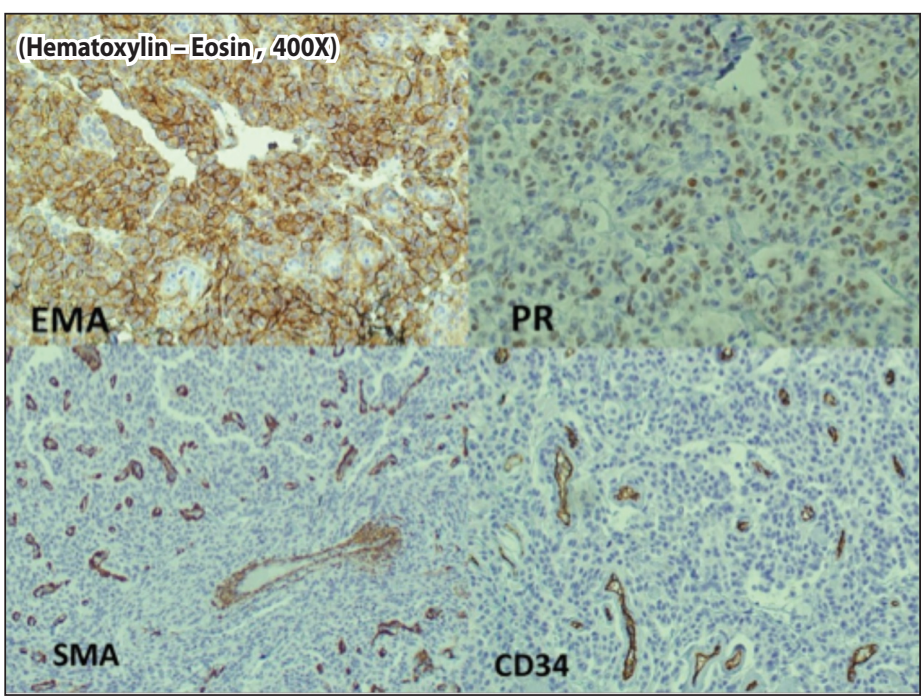

Figure 4. Immunohistochemistry showing Epithelial Membrane Antigen (EMA) and Progesterone Receptors (PR) positivity, and Smooth Muscle Actin (SMA) and CD34 non-reactivity (Horseradish peroxidase method, $400 \mathrm{X}$ magnification)

\footnotetext{
REFERENCES

1. Gnepp DR. Diagnostic Surgical Pathology of the Head and Neck. 2nd Edition. Philadelphia : PA: Saunders/Elsevier, 2009.p. 167.

2. Thompson LD, Gyure KA. Extracranial sinonasal tract meningiomas: a clinicopathologic study of 30 cases with a review of the literature. Am J Surg Pathol. 2000 May: 24(5):640-50. PMID: 10800982

3. Aiyer RG, Prashanth V, Ambani K, Bhat VS, Soni GB. Primary extracranial meningioma of paranasal sinuses. Indian J Otolaryngol Head Neck Surg. 2013 Aug: 65(Suppl 2): 384-387. DOI: 10.1007/s12070-012-0565-y; PMID: 24427682 PMCID: PMC3738789.

4. Ro JY, Bell D, Nicolai P, Thompson LDR. Meningioma. In: El-Naggar AK, Chan JKC, Grandis JR, Takata T, Slootweg PJ (editors). World Health Organization Classification of Head and Neck Tumours. Lyon: IARC Press. 2017. p. 50-51.
} 